\title{
Effect of sera from patients with rheumatoid arthritis on normal lymphocytes: a possible immunoregulatory role for immune complexes
}

\author{
J. HIGHTON, G. S. PANAYI, P. SHEPHERD, AND P. WOOLEY \\ From the Departments of Medicine, Rheumatology, and Chemical Pathology, Guy's Hospital Medical School, \\ London SE1 9RT
}

SUMMARY The ability of rheumatoid sera to support concanavalin-A transformation of normal lymphocytes was inversely related to serum $\mathrm{C} 1 \mathrm{q}$ binding activity. When $\mathrm{C} 1 \mathrm{q}$ binding activity of the sera was removed by absorption with staphylococcal protein $\mathrm{A}$, subsequent lymphocyte response increased to the level found in immune-complex negative sera. Gel filtration of a small number of sera suggested that the suppressive material had a molecular weight in the range $1.8-4.9 \times 10^{5}$ daltons. Aggregated human gammaglobulin suppressed con-A transformation of normal lymphocytes in a dose-dependent fashion. These results suggest that immune complexes present in rheumatoid sera can suppress lymphocyte responsiveness. The relevance of this observation to the clinical features of rheumatoid arthritis is discussed.

The lymphocyte is believed to play an important role in the pathogenesis of rheumatoid arthritis. ${ }^{1}$ This cell is prominent in affected tissues from the earliest stages of synovitis ${ }^{2-4}$ and lymphoblasts form a significant proportion of synovial fluid cells. ${ }^{5}$ Measures which alter lymphocyte function, such as thoracic duct drainage ${ }^{6}$ and irradiation of thoracic duct lymph, ${ }^{7}$ have an ameliorating effect on the disease. Other factors which alter lymphocyte function might therefore affect rheumatoid arthritis.

We have previously shown that the response of normal lymphocytes to concanavalin-A (con-A) in the presence of rheumatoid serum was inversely proportional to the $\mathrm{Clq}$ binding activity of the serum. ${ }^{8}$ Furthermore, sera taken from patients with active rheumatoid arthritis supported lymphocyte response to con-A less well than sera from the same patients after effective treatment. These observations suggested that immune complexes might be capable of depressing lymphocyte responsiveness, thereby contributing to the rheumatoid disease process. We have tested this hypothesis by further investigating the effect of sera from patients with rheumatoid arthritis on the response of normal lymphocytes to con-A.

Accepted for publication 23 October 1981.

Correspondence to $\mathrm{Dr}$ J. Highton, Wellcome Medical Research Institute, University of Otago Medical School, PO Box 913, Dunedin, New Zealand.

\section{Materials and methods}

PATIENT CHARACTERISTICS AND SERUM TECHNIQUES

Sera were collected from 37 patients with rheumatoid arthritis who were selected to represent a wide range of disease activity. The group included inpatients and outpatients. Disease characteristics and disease activity (duration of morning stiffness and number of active joints) were recorded by several observers. There were 26 females and 11 males, mean age $59 \cdot 5$ years (range $25-73$ years). Mean disease duration was 8.9 years (range $0 \cdot 3-30$ years). Twelve patients had nodules and 3 of these had nailfold vasculitic lesions. All patients were taking nonsteroidal anti-inflammatory drugs. In addition 9 were being treated with gold, 4 with D-penicillamine, 1 with chloroquine, and 1 with prednisone $7 \cdot 5 \mathrm{mg} /$ day. Sera were collected into sterile glass tubes and stored in aliquots in ethylene oxide sterilised plastic tubes at $-70^{\circ} \mathrm{C}$ prior to use. A reference control serum was made by pooling sera from 6 healthy staff members who were not on any medication.

Measurement of serum $C$-reactive protein. Serum CRP levels were measured by single radial immunodiffusion in $1 \%$ agar in phosphate buffered saline (PBS), $\mathrm{pH} 7 \cdot 2$, containing $0.2 \%$ goat anti-CRP (Seward). ${ }^{9}$

Serum $\mathrm{Cl} q$ binding activity. The $\mathrm{C} 1 \mathrm{q}$ subcom- 
ponent of complement was isolated from human serum by the method of Reid et al., ${ }^{10}$ and radioiodinated by the chloramine-T method of McConahey and Dixon. ${ }^{11}$ Specific radioactivity ranged from $0.4-0.8 \mu \mathrm{Ci} / \mu \mathrm{g} \mathrm{C} 1 \mathrm{q}$. The modified binding test was carried out as described by Zubler $e t$ al. ${ }^{12} \mathrm{C} 1 \mathrm{q}$ binding greater than $15 \%$ was taken to be abnormal and represents 2 standard deviations above the mean of a large number of normals previously tested.

Preparation of aggregated gammaglobulin. Human Cohn fraction II was dissolved in sterile distilled water at $20 \mathrm{mg} / \mathrm{ml}$ and insoluble material centrifuged out. An equal volume of $0 \cdot 2 \mathrm{M}$ sodium hydroxide was added and the mixture extensively dialysed against sterile phosphate buffered saline, $\mathrm{pH} 7 \cdot 2$. Aliquots were stored at $-70^{\circ} \mathrm{C}$ prior to use.

Absorption of sera with staphylococcal protein $A$. We absorbed 14 sera with staphylococcal protein A (staph A protein) linked to Sepharose 4B (Pharmacia) to remove IgG containing immune complexes. Staph A-4B was washed 10 times in sterile phosphate buffered saline containing gentamicin 5 $\mu \mathrm{g} / \mathrm{ml}$. Equal aliquots of staph A-4B were placed in plastic tubes (Luckams PT0944). The tubes were then centrifuged to remove PBS, and $0.6 \mathrm{ml}$ aliquots of the sera to be absorbed were added. The tubes were mixed on a roller at $4^{\circ} \mathrm{C}$ for 12 hours. As a control an exactly similar procedure was carried out at the same time with unconjugated Sepharose 4B (Pharmacia). After absorption the sera were centrifuged twice to remove Sepharose and stored at $-70^{\circ} \mathrm{C}$ prior to use in lymphocyte culture.

Fractionation of sera by gel filtration. A column of Sepharose CL-6B (Pharmacia), bed volume $2.5 \times 90$ $\mathrm{cm}$ was prepared and disinfected with $1 \%$ formaldehyde. The column was then eluted for 1 week with sterile phosphate buffered saline, $\mathrm{pH} 7 \cdot 2$, containing gentamicin $5 \mu \mathrm{g} / \mathrm{ml}$ to remove all traces of formaldehyde. The column was calibrated at an elution rate of $11 \mathrm{ml} /$ hour, collecting 20-minute fractions of $3 \cdot 7$ ml volume. $2 \mathrm{ml}$ serum samples from rheumatoid patients and normal persons were fractionated. Fractions were pooled in groups of 10 tubes $(37 \mathrm{ml})$ and concentrated under sterile conditions on a PM30 membrane (Amicon) in a $50 \mathrm{ml}$ stirred Amicon ultrafiltration cell at a pressure of 2 atmospheres nitrogen to give a final volume approximately the same as the starting serum volume. Concentrated, pooled fractions were stored at $-70^{\circ} \mathrm{C}$ prior to use in lymphocyte culture. For estimation of $\mathrm{C} 1 \mathrm{q}$ binding activity concentrated pooled fractions were diluted in an equal volume of normal serum. According to the column calibration the first 5 fractions would be expected to contain molecules of the following molecular weights: fraction $1,>3.8 \times 10^{6}$; fraction 2 ,
$1.4-3.8 \times 10^{6}$; fraction $3,4.9 \times 10^{5}-1.4 \times 10^{6}$; fraction $4,1.8-4.9 \times 10^{5} ;$ fraction $5,6.4 \times 10^{4}-1 \cdot 8$ $\times 10^{5}$.

\section{LYMPHOCYTE CULTURE}

Tissue culture medium. Cultures were carried out in Eagle's minimal essential medium (Gibco) buffered with $20 \mathrm{mM}$ hepes and $0.375 \%$ bicarbonate, and supplemented with $20 \mathrm{mM} \mathrm{L-glutamine}$ and gentamicin $5 \mu \mathrm{g} / \mathrm{ml}$.

Lymphocyte transformation. Blood from normal donors was anticoagulated with heparin $10 \mathrm{IU} / \mathrm{ml}$. Peripheral blood mononuclear cells were separated on Triosill/Ficoll gradients, ${ }^{13}$ washed twice in tissue culture medium (TCM), and adjusted to a concentration of $2.5 \times 10^{6} / \mathrm{ml} .2 \times 10^{5}$ cells per well were aliquoted into 96-well, flat-bottomed microtitre plates (Linbro) in $80 \mu \mathrm{l} \mathrm{TCM.} 20 \mu \mathrm{l}$ test serum was added to each well and incubated for 1 hour at room temperature and 1 hour at $37^{\circ} \mathrm{C}$. Concanavalin-A (Miles Laboratories) was added at a concentration of $20 \mu \mathrm{g} / \mathrm{ml}$. Thus each well contained $2 \times 10^{5}$ normal mononuclear cells in a total volume of $200 \mu \mathrm{l} \mathrm{TCM}$. The final test serum concentration was $10 \%$ and final con-A concentration $10 \mu \mathrm{g} / \mathrm{ml}$. Cultures were carried out in quadruplicate. Cultures containing normal pooled serum and fetal calf serum were included as controls. Plates were sealed with adhesive tape and incubated at $37^{\circ} \mathrm{C}$ for 72 hours. Tritiated thymidine $0.5 \mu \mathrm{Ci}$ (specific activity $5 \mathrm{Ci} / \mathrm{mM}$, Amersham Radiopharmaceuticals) was added to each well for the last 24 hours of culture. Lymphocytes were harvested on to filter paper with an Ilacon harvester. Thymidine incorporation was determined by counting in an LKB liquid scintillation $\beta$-counter and results expressed as mean disintegrations per minute (dpm) of quadruplicate cultures.

Lymphocyte cultures with staph-A absorbed sera. Cultures were carried out as previously described except for the substitution of absorbed sera.

Lymphocyte culture with aggregated gammaglobulin. Serial doubling dilutions of aggregated gammaglobulin were made in TCM. Cultures were carried out in triplicate in flat-bottomed wells as previously, each well containing $2 \times 10^{5}$ normal mononuclear cells, $10 \%$ pooled normal serum, con-A $10 \mu \mathrm{g} / \mathrm{ml}$, and aggregated human gammaglobulin in serial doubling dilutions from $500 \mu \mathrm{g} / \mathrm{ml}$ to $8 \mu \mathrm{g} / \mathrm{ml}$.

\section{LYMPHOCYTOTOXICITY OF SERA}

The ability of sera to kill lymphocytes was estimated at room temperature by a microlymphocytotoxicity technique ${ }^{14}{ }^{15}$ as described previously. ${ }^{16}$ For this experiment 28 sera were used. These were paired samples taken before and after gold treatment and were the same sera in which we initially demon- 


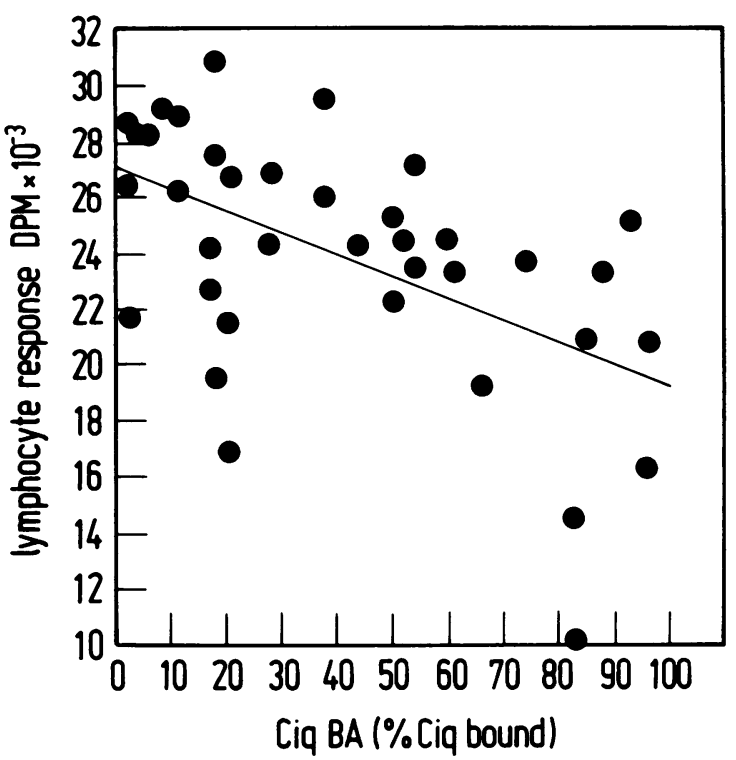

Fig. 1 Relationship between serum immune complex level measured as $\mathrm{Cl} q$ binding activity, and the response of normal peripheral blood mononuclear cells to concanavalin-A $10 \mu \mathrm{g} / \mathrm{ml}$ in the presence of $10 \%$ rheumatoid serum.

strated a relationship between serum $\mathrm{C} 1 \mathrm{q}$ binding activity and the response of lymphocytes in the presence of rheumatoid serum. ${ }^{8}$ A panel of lymphocytes from 12 normal donors was used. Killing of each donor's lymphocytes was estimated by trypan blue dye exclusion and was graded $0-4$. Overall lymphocytotoxicity of sera was expressed as a score derived by adding the lymphocytotoxicity grade for each of the 12 donor lymphocytes. Thus the highest possible lymphocytotoxicity score was 48 .
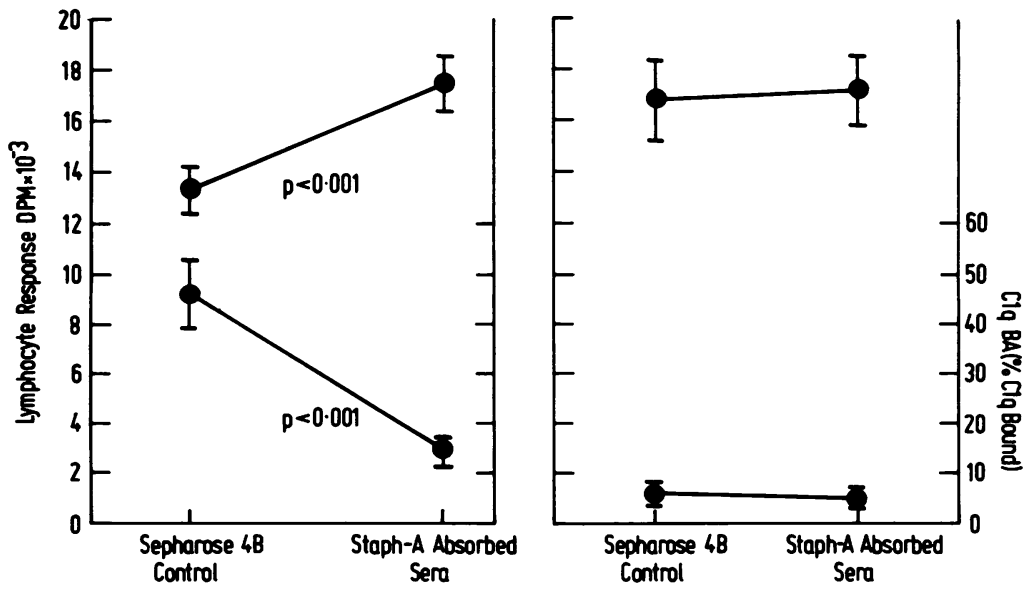

Lymphocyte transformation and Clq binding activity. There was a significant inverse correlation between the response to con-A of normal lymphocytes in the presence of rheumatoid serum, and serum $\mathrm{C} 1 \mathrm{q}$ binding activity $(r=-0.54, p<0 \cdot 001$, Fig. 1$)$. C1q binding activity was not related to either of the clinical measurements of disease activity (duration of morning stiffness or number of active joints).

Lymphocyte transformation and clinical disease activity. Lymphocyte response was related to 2 measurements of disease activity. There was a weak inverse relationship with duration of morning stiffness $(r=-0.36, p<0.05)$ and with serum CRP levels $(r=-0.52, p<0 \cdot 001)$. There was no significant difference in lymphocyte response assessed in sera from the patients with nodules (including the 3 patients with vasculitis) compared with that assessed in sera from patients without extra-articular features.

Staph-A absorption of sera. After control absorption with Sepharose 4B, 6 of the 14 sera had an elevated $\mathrm{C} 1 \mathrm{q}$ binding activity $(>15 \%)$ and 8 did not $(<15 \%)$. Mean $\mathrm{C} 1 \mathrm{q}$ binding activity of the 6 positive sera was $46 \pm 7 \%$ (mean \pm standard error of the mean) and of the 8 negative sera $6 \pm 2 \%$. After staph-A absorption mean $\mathrm{C} 1 \mathrm{q}$ binding activity of the 6 positive sera had fallen to $13 \cdot 7 \pm 3 \%$, indicating

Fig. 2 The effect of staphylococcal protein A (staph-A) absorption on the ability of rheumatoid sera to support concanavalin- $A$ transformation of normal lymphocytes. (a) Results from 6 sera containing immune complexes. The lower line shows that staph-A absorption effectively removed immune complexes, reducing $C 1 q B A$ to within the normal range. The upper line shows that after staph-A absorption sera are better able to support lymphocyte transformation. Results expressed as mean \pm standard error of the mean. (b) Results from 8 sera which contained no immune complexes. The lower line shows that staph-A absorption had no effect on serum C1q binding activity. The upper lines shows that in the absence of immune complexes staph- $A$ absorption had no effect on the ability of sera to support lymphocyte transformation. Results expressed as mean \pm standard error of the mean. 
that $\mathrm{Clq}$ binding immune complexes had been effectively absorbed (Fig. 2a). This fall is significant $(\mathrm{p}<0.001$, paired Student's $t$ test). There was no change in the $\mathrm{Clq}$ binding activity in the 8 negative sera (Fig. 2b).

Lymphocyte culture in staph-A absorbed sera. Staph-A absorption of the 6 sera containing immune complexes led to a significant increase in their ability to support lymphocyte transformation $(p<0 \cdot 001$, paired Student's $t$ test, Fig. 2a). Staph-A absorption made no difference to the ability of the immune complex negative sera to support lymphocyte transformation (Fig. 2b). After staph-A absorption sera which had previously contained immune complexes now supported lymphocyte transformation as well as the immune complex negative sera.

Lymphocyte culture with aggregated gammaglobulin. Aggregated gammaglobulin at a concentration of $500 \mu \mathrm{g} / \mathrm{ml}$ depressed the response of normal lymphocytes to con-A (12 $400 \pm 1200 \mathrm{dpm}$, mean \pm standard error of the mean, Fig. 3). With serial dilution of

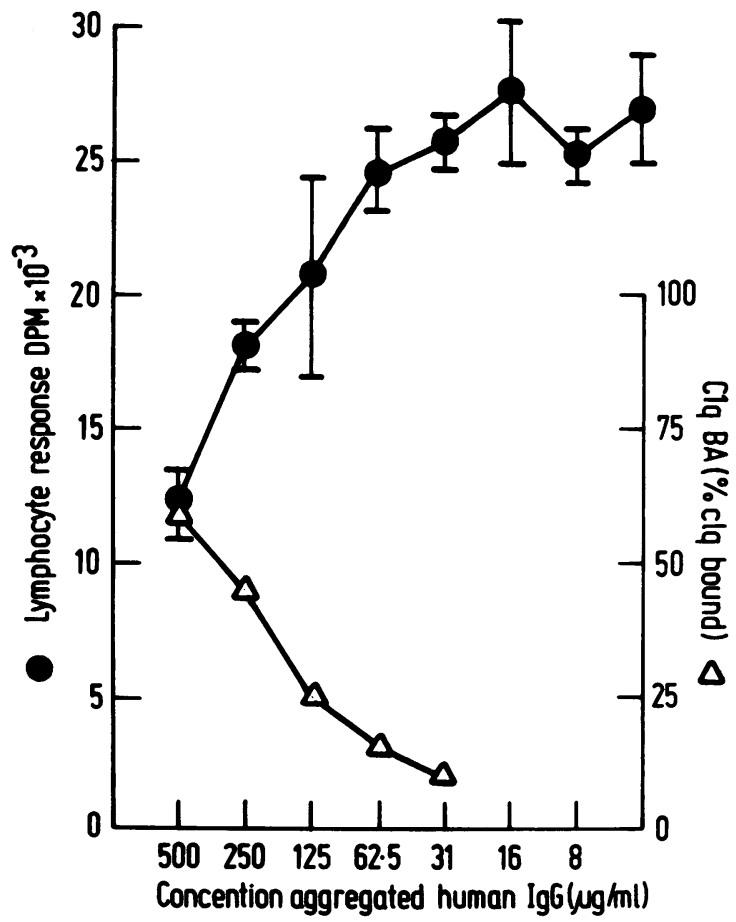

Fig. 3 Suppression of the con-A response of normal lymphocytes by the addition of aggregated gammaglobulin. The addition of aggregated gammaglobulin to normal serum is accompanied by the appearance of $\mathrm{Cl} q$ binding activity $(\Delta)$. The ability of such sera to support con- $A$ induced lymphocyte transformation of normal lymphocytes $(O)$ was related to the CIqBA of the sera. the aggregated gammaglobulin there was a progressive recovery of the lymphocyte response to a plateau reached at an aggregate concentration of $62.5 \mu \mathrm{g} / \mathrm{ml}$ $(24700 \pm 1700 \mathrm{dpm})$. Corresponding values for the

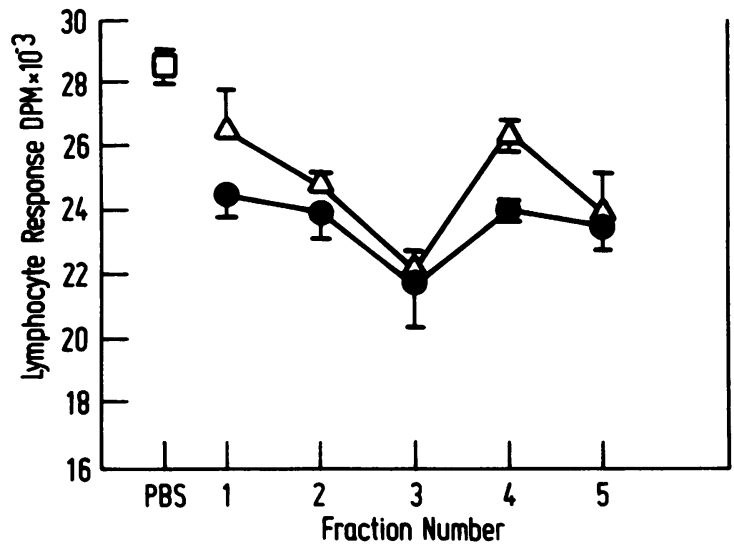

Fig. 4 The effect of column fractions of serum from patients with rheumatoid arthritis $(O, n=4)$ and from normal persons $(\Delta, n=3)$, on the concanavalin- $A$-induced transformation of normal lymphocytes. The only fraction in which rheumatoid sera support lymphocyte transformation less well is fraction $4(p<0 \cdot 05$, Student's paired t test). Results are shown as mean \pm standard error of the mean. Results from a control culture in which column buffer was added instead of serum fraction are shown ( $\square)$.

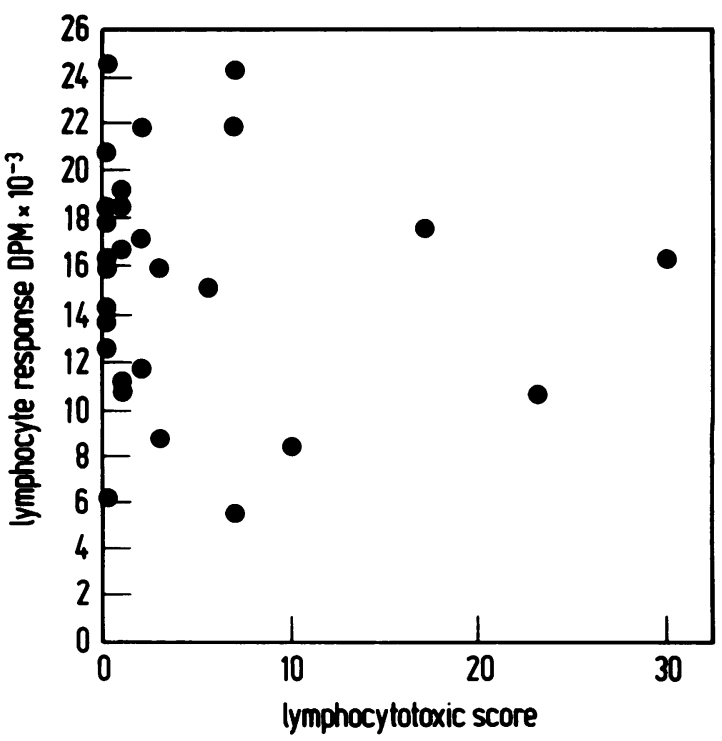

Fig. 5 Lack of relationship between serum lymphocytotoxicity and the response of normal peripheral blood lymphocytes to con-A $10 \mathrm{\mu g} / \mathrm{ml}$ in the presence of $10 \%$ rheumatoid serum. 
C1q binding activity of these aggregates are also shown in Fig. 3. It can be seen that in the presence of gammaglobulin aggregates at sufficient concentration to give an elevated $(>15 \%) \mathrm{C} 1 \mathrm{q}$ binding activity the lymphocyte response becomes depressed.

Lymphocyte culture with column fractions. Fig. 4 shows the response of normal lymphocytes to con-A in the presence of $10 \%$ pooled normal serum together with an equal concentration of each pooled, concentrated column fraction. The mean response is very similar for fractions from the 3 normal persons and 4 rheumatoid patients except in fraction 4 , where lymphocytes are seen to have responded significantly less well in rheumatoid sera $(p<0 \cdot 05$, paired Student's $t$ test). Fraction 4 has a calculated molecular weight range of $1.8-4.9 \times 10^{5}$ daltons.

Lymphocytotoxicity. There was no relationship between lymphocytotoxicity score of the sera tested and the response of normal lymphocytes to con- $\mathrm{A}$ in the presence of the same sera (Fig. 5).

\section{Discussion}

We have demonstrated a significant correlation between the response of normal lymphocytes to con-A in the presence of rheumatoid sera and the $\mathrm{C} 1 \mathrm{q}$ binding activity (C1qBA) of those sera. After staph-A absorption, which effectively removed immune complexes measured as $\mathrm{C} 1 \mathrm{qBA},{ }^{17}$ these sera supported lymphocyte transformation at the same level as control immune complex negative sera. Staph-A binds $\mathrm{IgG},{ }^{18}$ and although it reacts preferentially with aggregated IgG or immune complexes ${ }^{19}$ it could be expected to remove both $\mathrm{IgG}$ and IgG-containing immune complexes. Thus removal of either of these reactants could have been important in determining the increased capacity of these sera to support lymphocyte transformation.

Aggregated gammaglobulin, which possesses some of the properties of immune complexes, also inhibited the response of lymphocytes to con- $A$ in a dose-dependent fashion. This suppressive effect was first apparent at that concentration of gammaglobulin aggregate which produced detectable $\mathrm{C1q}$ binding activity. The reduced level of lymphocyte response seen at the highest concentration of aggregates tested (C1qBA $60 \%$ ), was similar to that seen with rheumatoid sera of similar C1q binding activity. A suppressive effect of gammaglobulin aggregates was also described by Antel et al. ${ }^{20}$ who showed that ${ }^{3} \mathrm{H}$-thymidine uptake in response to con-A was less if peripheral blood mononuclear cells were stimulated in the presence of such aggregates.

Our attempt to determine the size of immune complexes which might affect lymphocyte function was largely inconclusive, as no elevation of $\mathrm{C} 1 \mathrm{qBA}$ was observed in any of the concentrated fractions. This may have been due to losses during fractionation and concentration, ${ }^{21}$ and to the relative insensitivity of the $\mathrm{C} 1 \mathrm{q}$ binding assay, particularly as fractions were diluted in normal serum prior to assay. Thus it is possible that immune complexes were present in particular fractions but remained undetected. In spite of this, and the small number of sera fractionated, it is interesting to note that fraction 4 , which is the fraction in which intermediate molecular weight complexes would appear, was the only one in which a significant difference between rheumatoid sera and normal sera was seen. Furthermore this makes it unlikely that monomeric IgM or IgG antibodies were responsible for this effect as they would be expected to appear in fractions 3 and 5 respectively. This is consistent with the lack of correlation between lymphocyte response and lymphocytotoxins, which when measured by the technique employed would be largely of the IgM class. ${ }^{22}$ Because column fraction 3 was the most 'suppressive' fraction in both rheumatoid patients and normal persons it is likely that other factors, such as con-A binding ${ }^{23}{ }^{24}$ may also be important in determining the response of lymphocytes to con-A in this system.

Antel et al. ${ }^{20}$ have shown that preincubation of gammaglobulin aggregates with normal peripheral blood mononuclear cells leads to the generation of suppressor cells, probably T cells, capable of suppressing the response of fresh lymphocytes to con-A. These authors used aggregates which eluted from a Sepharose 6B column in a position similar to our fraction 4 . This suggests that generation of suppressor cells by rheumatoid immune complexes might be the mechanism producing the effect on lymphocyte function which we have observed.

To examine the possibility that our observations might be relevant to clinically apparent rheumatoid disease we looked for a relationship between the effect of patients' sera on lymphocytes and clinical characteristics. We hypothesised that patients with 'lepromatous' rheumatoid arthritis, ${ }^{25}$ in whom nodules, vasculitis, and other extra-articular features thought to be related to immune complexes dominate the picture, would have the most suppresssive sera. However, we did not find this to be the case, largely due to a number of patients with high levels of immune complexes whose sera strongly suppressed lymphocyte response but who did not have nodules or vasculitis. Although serum $\mathrm{C1q}$ binding activity was not related to morning stiffness or number of active joints, which is in agreement with our previous report, ${ }^{26}$ there was some relationship between serum effect on lymphocytes and disease activity assessed by morning stiffness and CRP levels.

These results suggest that rheumatoid immune 
complexes may contribute to the depression of lymphocyte responsiveness observed in active rheumatoid arthritis, ${ }^{8}$ and that this may be another mechanism by which immune complexes could contribute to the pathogenesis of the disease.

During this study John Highton was supported by funds from an Arthritis and Rheumatism Council fellowship. The work was also supported by funds from an Arthritis and Rheumatism Council programme grant to Professor G. S. Panayi. We would like to thank Ms P. Burke for technical assistance in the estimation of $\mathrm{C} 1 \mathrm{q}$ binding activity.

\section{References}

${ }^{1}$ Panayi G S, Corrigall V. Lymphocyte function in rheumatoid arthritis. In: Panayi G S, Johnson P M, eds. Immunopathogenesis of Rheumatoid Arthritis. Chertsey, Surrey: Reed Books, 1978: 3-6.

${ }^{2}$ Kulka J P, Bocking D, Ropes M W, Bauer W. Early joint lesions of rheumatoid arthritis. Arch Pathol 1955; 59: 129-50.

${ }^{3}$ Schumacher H R, Kitridou R C. Synovitis of recent onset. A clinicopathologic study during the first month of disease. Arthritis Rheum 1972; 15: 465-85.

${ }^{4}$ Schumacher H R. Synovial membrane and fluid morphologic alterations in early rheumatoid arthritis: microscopic vascular injury and virus-like particles. Ann NY Acad Sci 1975; 256: 39-64.

5 Traycoff R B, Pascual E, Schumacher H R. Mononuclear cells in human synovial fluid: identification of lymphoblasts in rheumatoid arthritis. Arthritis Rheum 1976; 19: 743-8.

${ }^{6}$ Pearson CM, Paulus H E, Machleder H I. The role of the lymphocyte and its products in the propagation of joint disease. Ann NY Acad Sci 1975; 256: 150-68.

${ }^{7}$ Edgren J, Klockars M, Weber T, et al. Extracorporeal irradiation of thoracic duct lymph as immunosuppressive treatment in rheumatoid arthritis. Scand J Rheumatol 1976; 6: 108-12.

${ }^{8}$ Highton J, Panayi G S, Shepherd P, Griffin J, Gibson T. Changes in immune function in patients with rheumatoid arthritis following treatment with sodium aurothiomalate. Ann Rheum Dis 1981;40: 254-62.

- Mancini G, Carbonara A O, Heremans J F. Immunochemical quantitation of antigens by single radial immunodiffusion. Immunochemistry 1965; 2: 235-54.

${ }^{10}$ Reid K B M, Lowe D M, Porter R R. Isolation and characterisation of $\mathrm{C} 1 \mathrm{q}$, a subcomponent of the first component of complement, from human and rabbit sera. Biochem J 1972; 130: 749-63.
${ }^{11}$ McConahey P J, Dixon F J. A method of trace iodination of proteins for immunologic studies. Int Arch Allergy Appl Immunol 1966; 29: 185-9.

12 Zubler R H, Lange G, Lambert P H, Miescher P A. Detection of immune complexes in unheated sera by a modified ${ }^{125} \mathrm{I}$-labelled C1q binding test. $J$ Immunol 1976; 116: 232-5.

${ }^{13}$ Boyum A. Isolation of mononuclear cells and granulocytes from human blood. Scand J Clin Lab Invest 1968; 21 (suppl 97): 77-89.

${ }_{14}$ Terasaki P I, McClelland J D. Microdroplet assay of human serum cytotoxins. Nature 1964; 204: 998-1000.

${ }^{15}$ Mittal K K, Mickey M R, Singal D P, Terasaki P I. Serotyping for homotransplantation. XVIII. Refinement of microdroplet lymphocyte cytotoxicity test. Transplantation 1968; 6: 913-27.

16 Wooley P H, Panayi G S, Batchelor J R. Lymphocytotoxins in rheumatoid arthritis: prevalence, lymphocyte specificity and HLA DR antigens. Ann Rheum Dis 1981; 40: 154-6.

${ }^{17}$ Lawley T J, Moutsopoulos H M, Katz S I, Theofilopoulos A N, Chused T M, Frank M M. Demonstration of circulating immune complexes in Sjögren's syndrome.J Immunol 1979; 123: 1382-7.

${ }^{18}$ Forsgren A, Sjoquist J. Protein A from S. aureus. I. Pseudoimmune reaction with human $\gamma$-globulin. J Immunol 1966; 97: $822-7$.

19 McDougal J S, Redecha P B, Inman R D, Christian C L. Binding of immunoglobulin $G$ aggregates and immune complexes in human serum to staphylococci containing protein A.J Clin Invest 1979; 63: 627-36.

${ }^{20}$ Antel J P, Medof M E, Oger J J-F, Kuo H-H, Arnason B G W. Generation of suppressor cells by aggregated human globulin. Clin Exp Immunol 1981; 43: 351-6.

21 Yue R, Tackaberry E, McAvoy D, Shustik C, Broder I. Antigenantibody complexes in disease. VIII. Fractionation of rheumatoid samples containing immune complex-like material. J Rheumatol 1978; 5: 252-62.

${ }_{22}$ Terasaki P I, Mottironi V D, Barnett E V. Cytotoxins in disease. Autocytotoxins in lupus. $N$ Engl J Med 1970; 283: 724-8.

${ }^{23}$ Warren C, Whicher J, Kohn J. The use of concanavalin A to measure acute phase proteins by laser nephelometry.J Immunol Methods 1980; 32: 141-50.

24 Tanimoto K, Moritoh T, Azuma T, Horiuchi Y. Detection of IgG rheumatoid factor by concanavalin $A$ treatment and complement fixation with IgG rheumatoid factor. Ann Rheum Dis 1976; 35: 240-5.

${ }^{25}$ Panayi G S. Pathogenesis of rheumatoid arthritis. Eur $J$ Rheumatol Inflamm 1979; 2: 265-71.

${ }^{26}$ Highton J, Panayi G S, Shepherd P, Faith A, Griffin J, Gibson T. Fall in immune complex levels during gold treatment of rheumatoid arthritis. Ann Rheum Dis 1981; 40: 575-9. 